\title{
Raman imaging studies on the adsorption of methylene blue species onto silver modified linen fibers
}

\author{
Sara Fateixa, ${ }^{a *}$ (๑) Manon Wilhelm, ${ }^{a}$ Alípio M. Jorge, ${ }^{b}$ Helena I. S. Nogueira ${ }^{a}$ \\ and Tito Trindade ${ }^{a}$
}

\begin{abstract}
We demonstrate in this research that surface-enhanced resonance Raman scattering combined with Raman imaging can be effectively used for analysis of distinct forms of organic dyes in antimicrobial Ag-loaded textile fibers. The potential of this approach, as a non-destructive characterization method of fabrics, was evaluated with Raman studies performed on the molecular forms of methylene blue (MB), used here as the organic dye model. On the basis of the surface-enhanced Raman scattering spectra of MB monomers and dimers, the Raman imaging of Ag-loaded linen fibers previously treated with MB solution was performed and then used for identification of the adsorbate species in distinct regions of the substrates. A semi-quantitative analysis is then performed by considering the area of the Raman bands ascribed to the MB molecular forms and image analysis applied to Raman images. Copyright $\odot 2017$ John Wiley \& Sons, Ltd.
\end{abstract}

Keywords: Raman imaging; surface-enhanced resonance Raman scattering; textile fibers; methylene blue species

\section{Introduction}

It is well known that molecular association affects the color and photo-physical properties of dyes in solution. ${ }^{[1-8]}$ The formation of molecular aggregates due to electrostatic attraction depends on several factors such as dye concentration, ionic strength of the medium, temperature, solvent, and $\mathrm{pH} .{ }^{[7,9-13]}$ In conditions of low dye concentration, molecular association might lead to dimers or even higher order aggregates. ${ }^{[9,14]}$ For example, methylene blue (MB), a widely used thiazine dye, when dissolved in water establishes equilibrium between dimers and monomers, whose optical absorption spectra are distinct. ${ }^{[6,7,15]}$ In MB aqueous solution, the monomer shows maximum absorption at $662 \mathrm{~nm}\left(\varepsilon=3.88 \times 104 \mathrm{Lmol}^{-1} \mathrm{~cm}^{-1}\right)$ while the dimer has an absorption maximum at $610 \mathrm{~nm}$ $\left(\varepsilon=9.06 \times 104 \mathrm{Lmol}^{-1} \mathrm{~cm}^{-1}\right) .{ }^{[16,17]}$ Bujdák et al. ${ }^{[18]}$ have reported the presence of $\mathrm{MB} \mathrm{H}$-aggregates (face-to-face cations), absorbing at $570 \mathrm{~nm}$ and high-order $\mathrm{H}$-aggregates absorbing at $525 \mathrm{~nm}^{[19]}$ The presence of protonated methylene blue $\left(\mathrm{MBH}^{2+}\right)$ molecular cations and J-aggregates (head-to-tail cations) absorbing at $770 \mathrm{~nm}$ was also described. ${ }^{[20]}$

For the study of the MB forms in aqueous solution, several methods have been employed, including fluorescence quenching monitoring and optical absorption studies in conditions of high concentration (deviation from the Beer's law).$^{[6,7,15]}$ More recently, surface-enhanced Raman scattering (SERS) was also explored by using silver and gold electrodes as substrates for $M B$ adsorbates. ${ }^{[16,21]}$ Hence, Corn et al. have investigated the adsorption of MB monolayers onto the surface of gold and sulfur-modified gold electrodes using laser-induced fluorescence spectroscopy and Fourier transform SERS. ${ }^{[21]}$ Nicolai et al. have reported surface-enhanced resonance Raman scattering studies on $\mathrm{MB}$ adsorbed onto an $\mathrm{Ag}$ electrode, describing the formation of monomeric $M B$ in equilibrium with higher order aggregates at the electrode surface. ${ }^{[16]}$
The surface-enhanced resonance Raman scattering is achieved when a Raman active molecule has a chromophore group with electronic transitions in resonance with the frequency of the laser source used in Raman, which will also excite the plasmon of the metallic substrate and create the SERS effect. ${ }^{[22-24]}$ Thus, it is a particular case of SERS but with the main advantage that fluorescence emission interference that might obscure the Raman signal can be in this case attenuated, creating enhancement factors in same cases of the order $10^{11}-10^{12}$, which allow chemical analysis to very low detection limits. ${ }^{[22,24,25]}$ In this research, both enhancement from non-resonant SERS of the roughened Ag surface and the resonance Raman signal of the MB will be exploited.

It is important to note that studies of dye molecular forms present at solid surfaces are of great and practical relevance, for example, in textile fibers dyeing. Indeed, the adsorption of cationic dyes onto solid surfaces often results in color changes as compared with the dissolved species in water. This metachromatic effect can result from the nature and relative amount of the molecular forms adsorbed at the surfaces, which can be monomeric species, dimers, and also higher order aggregates. ${ }^{[18,26]}$ Although electronic spectra of dyed fabrics provide useful information for such type of studies, there are limitations concerning the nanoscale characterization of the molecular aggregates adsorbed at the surfaces. In a recent

\footnotetext{
* Correspondence to: Sara Fateixa, Department of Chemistry, CICECO-Aveiro Institute of Materials, University of Aveiro, Campus de Santiago, 3810-193 Aveiro, Portugal. E-mail: sarafateixa@ua.pt

a Department of Chemistry, CICECO-Aveiro Institute of Materials, University of Aveiro, Campus de Santiago, 3810-193, Aveiro, Portugal

b LIAAD-INESC TEC, DCC/FCUP, University of Porto, R. Dr. Roberto Frias, 4200, Porto, Portugal
} 
study published in this journal, we have demonstrated that the combined use of SERS and Raman imaging is a powerful tool to analyze organic dyes adsorbed onto antimicrobial fabrics by using MB and Ag-loaded linen fibers as the materials of study. ${ }^{[27]}$ Although our report provided a method to acquire a better understanding of the distribution of Ag nanoparticles (NPs) in antimicrobial fabrics, the study of molecular association of MB used as dye onto the fabrics remained an open issue. This aspect is particularly relevant by considering that in certain cases the color conferred by the dye depends on the aggregation state of their molecules, but this effect has been scarcely addressed in the literature. In particular for MB, to the best of our knowledge, there are no studies reporting the molecular forms retained in textile fibers during the dyeing process. In order to fill this gap, we have carried out a Raman imaging study on those systems in order to assess the distinct molecular forms of MB present at the Ag-loaded linen fibers. We anticipate that the approach described here can be applied to other hybrid SERS substrates available, such as nanocomposites based on polymers of natural and synthetic origin. ${ }^{[28,29]}$

\section{Materials and methods}

\section{Materials}

The following chemicals were used as purchased: silver nitrate $\left(\mathrm{AgNO}_{3}, 99.9 \%\right.$, J. M. Vaz Pereira), sodium citrate tribasic dihydrate $\left(\mathrm{Na}_{3} \mathrm{C}_{6} \mathrm{H}_{5} \mathrm{O}_{7} \cdot 2 \mathrm{H}_{2} \mathrm{O}\right.$, 99\%, Sigma-Aldrich), and $\mathrm{MB}\left(\mathrm{C}_{16} \mathrm{H}_{18} \mathrm{~N}_{3} \mathrm{SCl}\right.$, Riedel-De Haën). The linen fibers were kindly supplied by CENTI, Vila Nova de Famalicão, Portugal.

\section{Preparation of Ag/linen nanocomposites}

The Ag/linen nanocomposites were prepared as follows. The linen fibers $(250 \mathrm{mg}$ ) were placed into $50 \mathrm{~mL}$ of an aqueous solution of $\mathrm{AgNO}_{3}(1 \mathrm{mM})$. The mixture was heated under reflux over $10 \mathrm{~min}$, and then $1 \mathrm{~mL}$ of sodium citrate solution $(1 \% \mathrm{w} / \mathrm{v})$ was added dropwise under vigorous stirring. The mixture was then refluxed for $45 \mathrm{~min}$ and slowly cooled to room temperature. The ensuing nanocomposite fibers were then removed by filtration, thoroughly washed with deionized water and dried overnight in an oven at $70^{\circ} \mathrm{C}$.

\section{Raman imaging and image analysis}

The adsorption of MB onto Ag NPs surface was investigated using the $\mathrm{Ag}$ /linen composites as SERS substrates. Aqueous solutions of $\mathrm{MB}$ with varying concentrations (from 100 to $1 \mu \mathrm{M}$ ) and ethanol solution $(100 \mu \mathrm{M})$ have been prepared by dissolving the respective amount of MB powder in the solvent, at room temperature. All samples for Raman imaging were prepared by addition of $10 \mu \mathrm{L}$ of the $\mathrm{MB}$ solution to the surface of the $\mathrm{Ag} / \mathrm{linen}$ nanocomposites and dried at room temperature.

The WITec software, WITec Project 2.0 (WITec, Ulm, Germany), was used to create the Raman images. The Raman spectra of the monomer and of the dimer and monomer mixture were used as the basis set in the analysis using the software tool of WITec Project, providing the color-coded combined Raman images. The Raman images showing a color scale have been created using band integrals, in which the value of the absolute area underneath a band (e.g. at $445 \mathrm{~cm}^{-1}$ ) corresponds to a color intensity in the scale, shown in the image at the respective pixels.
The deconvoluted Raman spectra were obtained by applying the command fitting multi-peaks using the Gaussian function in origin 8. The image analysis was performed using the tiff files. For each image, three color channels (RGB) were separated and counted the number of pixels corresponding to the visible colors 'blue' and 'red'. Each channel can be seen as a vector of values in the interval $[0,1]$. The criteria for considering a pixel 'blue' are to satisfy ' $R \leq 0.3$ AND $B \geq 0.7$ AND $G \leq 0.3^{\prime}$. A 'red' pixel satisfies ' $R \geq 0.7$ AND $B \leq 0.3$ AND $G \leq 0.3^{\prime}$. The proportion of 'blue' is the ratio between the number of blue points and the total number of pixels, similarly for the proportion of 'red'. Image processing was performed using our own $\mathrm{R}^{[30]}$ using the packages 'pixmap ${ }^{\text {[31] }}$ and 'rtiff'. ${ }^{[32]}$

\section{Instrumentation}

A Jasco V 560 UV/visible (UV/vis) spectrophotometer was used for recording the UV/vis spectra of the samples. Scanning electron microscope (SEM) images were obtained using a Hitachi SU-70 SEM (Hitachi High-Technologies, Tokyo, Japan); Raman imaging has been performed using a combined Raman-AFM-SNOM confocal microscope WITec alpha300 RAS+ (WITec, Ulm, Germany). Raman images were produced by raster scanning the laser beam over the samples and by accumulating a full Raman spectrum at
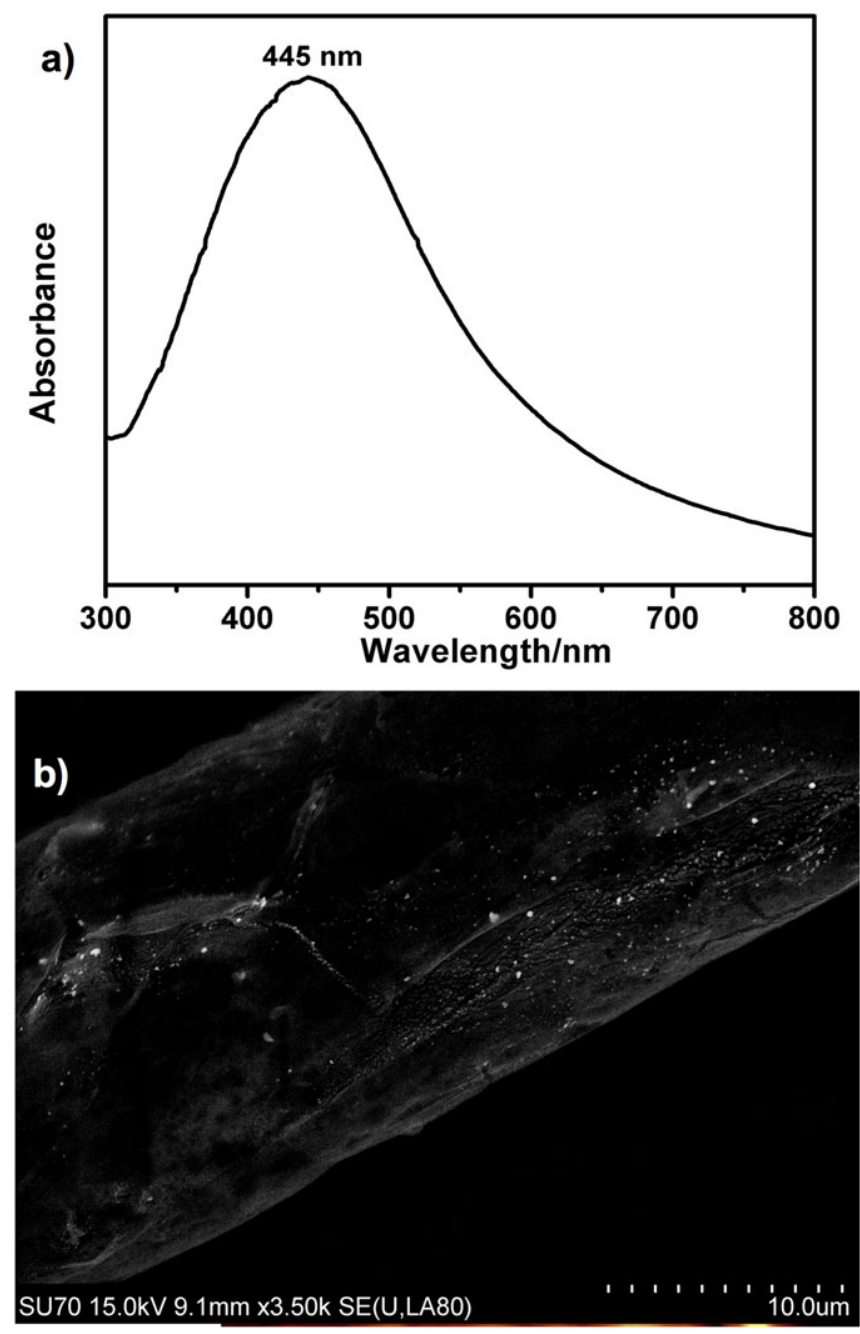

Figure 1. (a) Visible spectrum (Kubelka-Munk converted reflectance spectra) of Ag/linen composite; (b) SEM backscattered electron mode image of Ag/linen composite. [Colour figure can be viewed at wileyonlinelibrary.com] 


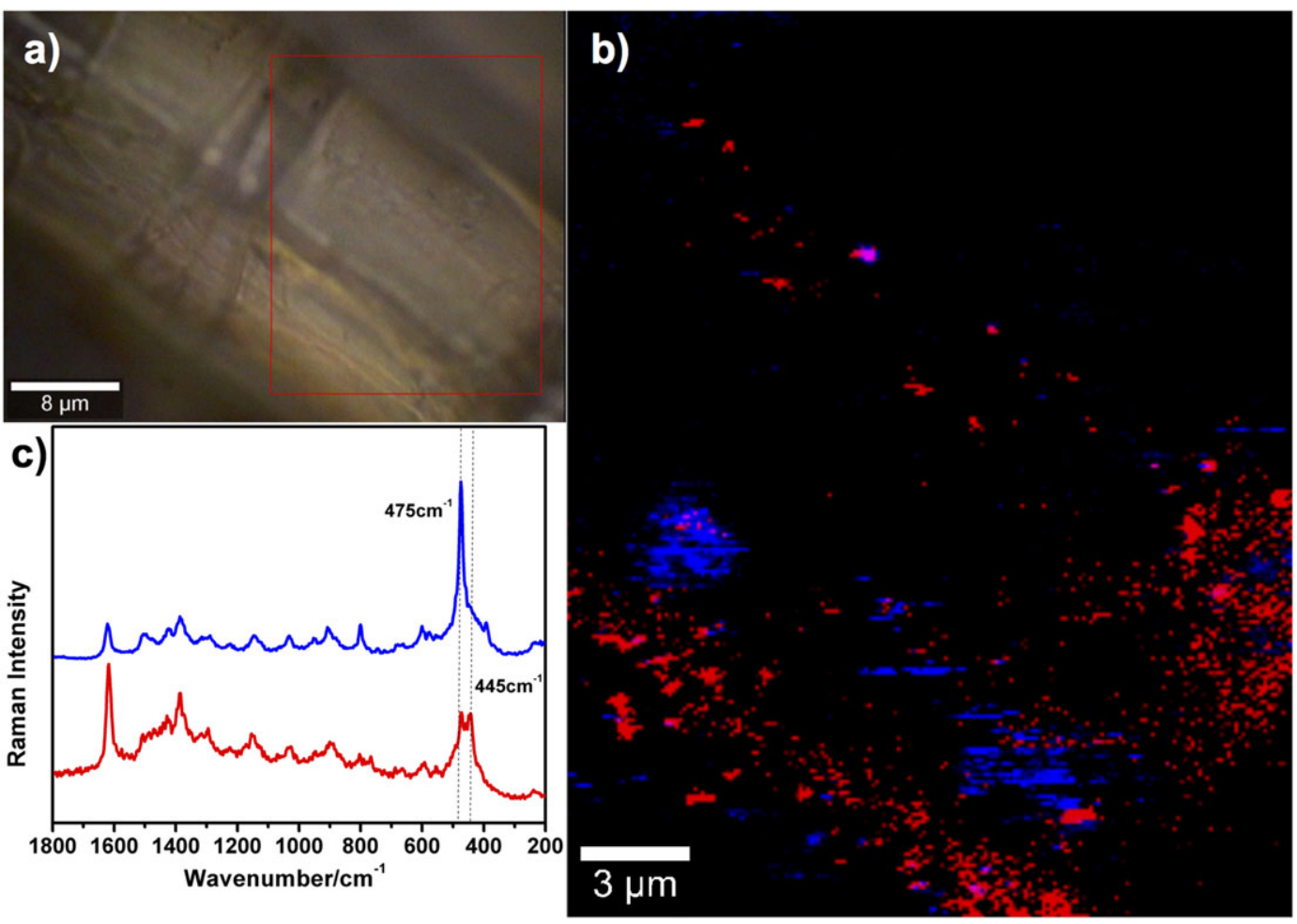

Figure 2. Optical photograph (a) and combined Raman image (b) using two different Raman spectra of methylene blue (100 $\mu \mathrm{M})$ adsorbed on Ag/linen composite $(633 \mathrm{~nm}$ excitation laser source, $300 \times 340$ points per grid in a $30 \times 35 \mu \mathrm{m}$ area); (c) Raman spectra used for the combined Raman image. [Colour figure can be viewed at wileyonlinelibrary.com]

each pixel. An He : Ne laser operating at $633 \mathrm{~nm}$ and an Nd : YAG laser operating at $532 \mathrm{~nm}$ were used as excitation sources, both with the power set at $2 \mathrm{~mW}$.

\section{Results and discussion}

The increasing use of antimicrobial fabrics containing Ag in their composition prompted great interest in studying these materials

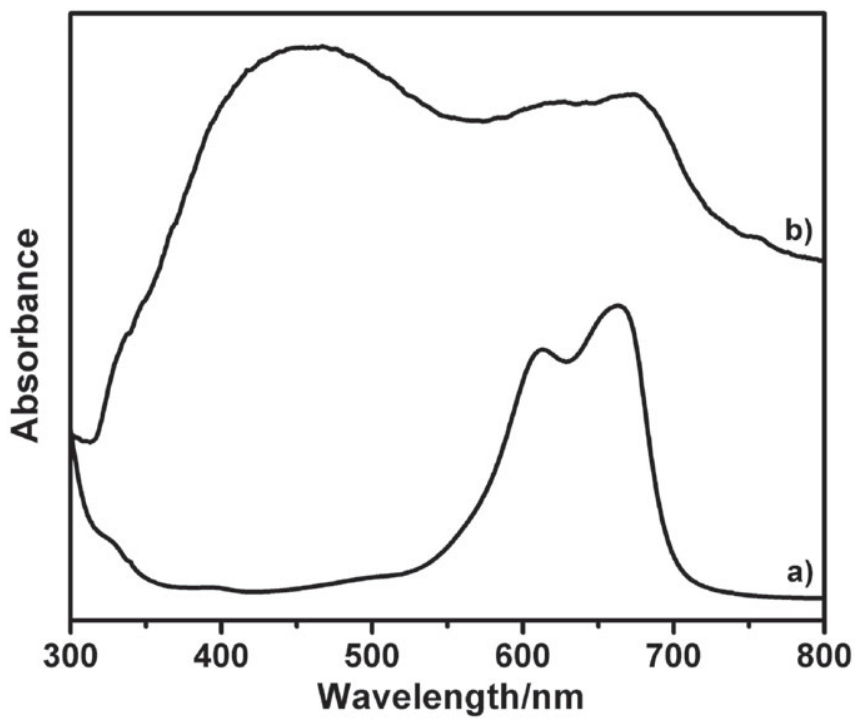

Figure 3. Visible spectra of (a) methylene blue aqueous solution (100 $\mu \mathrm{M})$ and (b) Ag/linen composite with a drop of methylene blue $(100 \mu \mathrm{M})$ (Kubelka-Munk converted reflectance spectra). by non-conventional characterization techniques. For instance, the presence of Ag nanoparticles (NPs) in their composition allows the analysis of these materials by innovative Raman methods, thus taking advantage of the presence of SERS active metal NPs. Figure 1 shows the UV/vis spectrum and SEM images for the Ag-loaded linen fibers used in this research. The UV/vis spectrum of the Ag/linen fibers shows the localized surface plasmon resonance band of $\mathrm{Ag}$ NPs, peaked at $445 \mathrm{~nm}$. The SEM image shows well-distributed Ag NPs over the linen surfaces.

As expected, the Ag/linen composite fibers acquired a blue color after treatment with the MB aqueous solution, and then the ensuing materials were analyzed by Raman spectroscopy. Overall, the Raman spectrum (Fig. S1) of this sample is dominated by the characteristic bands of $\mathrm{MB}$, and the respective vibrational modes assignments have been reported. ${ }^{[27,33-36]}$ For the purposes of this research, a more detailed analysis was focused on the bands at $445 \mathrm{~cm}^{-1}$ (CN skeletal deformation) and on the thiazine group inplane bending mode at $475 \mathrm{~cm}^{-1}$. Indeed, such vibrational bands in the Raman spectrum can be used as indicative for the presence of the monomer and dimer forms of MB. Hence, the band at $475 \mathrm{~cm}^{-1}$, assigned to the thiazine group in-plane bending mode, is associated with the monomer, while the band at $445 \mathrm{~cm}^{-1}$ is due to the formation of MB dimers. ${ }^{[16,37-39]}$ Several studies have demonstrated that by monitoring the relative intensities of the vibrational bands at $445 \mathrm{~cm}^{-1}$ (CN skeletal deformation) and $475 \mathrm{~cm}^{-1}$ (thiazine group in-plane bending), the amount of $\mathrm{MB}$ monomers in relation to MB dimers, both in solution and onto solid surfaces, can be followed. ${ }^{[16,37-39]}$ Figure 2 shows a 2D Raman imaging that combines the two distinct SERS spectra of MB identified in the Ag/linen nanocomposites. The spectrum corresponding to the monomer (blue tracing) shows a strong band at $475 \mathrm{~cm}^{-1}$ while the spectrum corresponding to a mixture of monomer/dimer (red 
tracing) shows bands at 445 and $475 \mathrm{~cm}^{-1}$. In the latter, the intensity of the band at $475 \mathrm{~cm}^{-1}$ is comparable with the intensity of the band at $445 \mathrm{~cm}^{-1}$. The observation of both MB forms is an important finding for the current study because it excludes the hypothesis that regardless the type of Ag NPs distribution within the fibers, just one of the MB forms would be detected by SERS. This means that both MB forms can be detected in these SERS substrates by using the experimental setup employed here. These results are in agreement with previous reports that described both the monomer and dimer MB adsorbates onto silver electrodes, ${ }^{[16]}$ gold films, ${ }^{[39]}$ and membrane mimetic systems. ${ }^{[37,38]}$ Moreover, the UV/Vis spectrum of the Ag/linen nanocomposite (Fig. 3) shows two overlapping bands in the 600 to $700 \mathrm{~nm}$ region, corresponding to the monomer and dimer, which was also observed in the starting aqueous solution containing the dye. Also note the broad band peaked at $445 \mathrm{~nm}$, which is due to the presence of Ag NPs in the linen fibers, as mentioned previously.

A distinct question concerns the SERS sensitivity of the MB species adsorbed onto the substrates, either monomers or dimers. Taking into account the wavelength region delimited by the maximum absorption of each MB form, $610 \mathrm{~nm}$ for the dimer and $670 \mathrm{~nm}$ for the monomer, the use of an excitation line whose wavelength $(633 \mathrm{~nm})$ is within such spectral absorption region leads to Raman signal enhancement for both forms because of resonance effects (surface-enhanced resonance Raman scattering). ${ }^{[16]}$ Conversely, Raman imaging using laser line out of resonance $(532 \mathrm{~nm})$ shows the bands at 445 and $505 \mathrm{~cm}^{-1}$ assigned to the dimer species of $\mathrm{MB}$, but the band assigned to the monomer form $\left(475 \mathrm{~cm}^{-1}\right)$ is not clearly distinguished from the background noise (Fig. 4). This result indicates that in conditions of non-resonance (532-nm excitation), only Raman bands of the dimer form have been enhanced, which is in agreement with reported literature. ${ }^{[16]}$ Therefore, our subsequent Raman studies in these systems were carried out using the excitation line at $633 \mathrm{~nm}$, because in this case, both MB forms could be detected by SERS.

The Raman images presented previously show that by treating the Ag/linen fibers with an MB solution $100 \mu \mathrm{M}$, both monomer and dimer MB species adsorbed onto the Ag NPs surfaces dispersed in the linen fibers. As shown in Fig. 5, similar experiments but using aqueous solutions of lower concentration in MB (10 and $1 \mu \mathrm{M})$ indicate the presence of monomers (band at $475 \mathrm{~cm}^{-1}$ ) and dimers (band at $445 \mathrm{~cm}^{-1}$ ). However, the latter was always observed as more intense in the several Raman spectra recorded over different regions of the loaded fibers, which suggests that $M B$ dimers predominate as adsorbates when using starting solutions of low concentration of the dye. ${ }^{[9,14]}$

The aforementioned results indicate that MB monomers and dimers adsorb onto the Ag NPs spread over the fibers surfaces. An interesting point at this stage is to find out if this methodology provides information concerning the presence of $\mathrm{MB}$ species in the interior of the fibers. First, it should be noted that this type of SERS analysis is possible because Ag NPs are also present in the interior of the fibers. ${ }^{[27]}$ Therefore, deep Raman imaging of MB through the Ag/linen fibers was performed along the Z-axis and by monitoring the respective Raman bands assigned to the monomers and dimers. Figure 6 shows the optical image and the combined 2D deep Raman image of the Ag/linen fibers.

Two main observations result from the analysis of Fig. 6 . First, the confirmation that the SERS signal is observed for MB adsorbed at the surface and also in the interior of the Ag-loaded linen fibers. The latter allows us to confirm that the interior of the fibers contain Ag NPs, which probably have been generated during the reduction
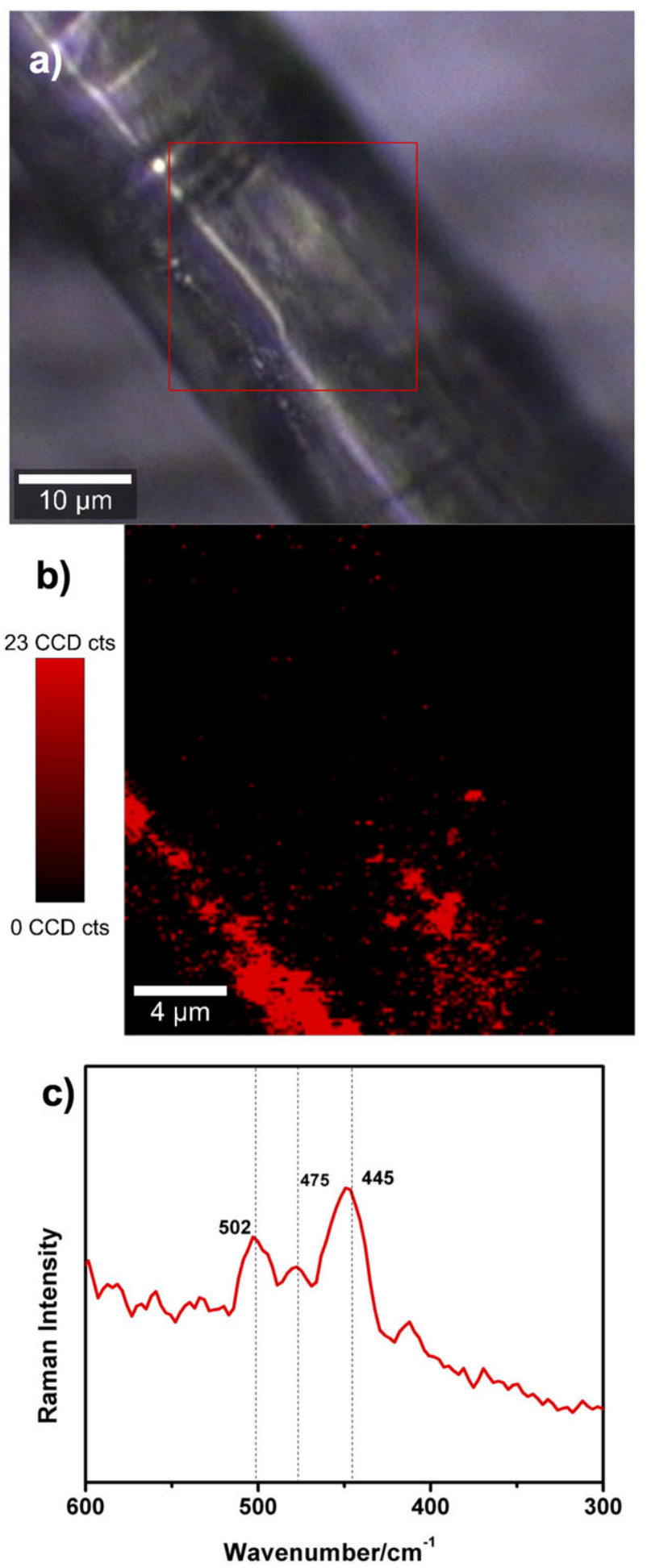

Figure 4. Optical photograph (a) and Raman image (b) obtained using the integrated intensity of the Raman band at $445 \mathrm{~cm}^{-1}$ in the SERS spectra of methylene blue $(100 \mu \mathrm{M})$ adsorbed on Ag/linen (excitation at $532 \mathrm{~nm}$, $2 \mathrm{~mW}$ laser power, $150 \times 150$ points per grid in a $22 \times 22 \mu \mathrm{m}$ area, $0.01 \mathrm{~s}$ ). The vertical bar shows the color profile in the Raman image; (c) average Raman spectrum obtained from the Raman image data. [Colour figure can be viewed at wileyonlinelibrary.com]

of cationic silver previously loaded in the linen. Experiments using linen fibers without Ag NPs did not show Raman bands for MB but fluorescence. 

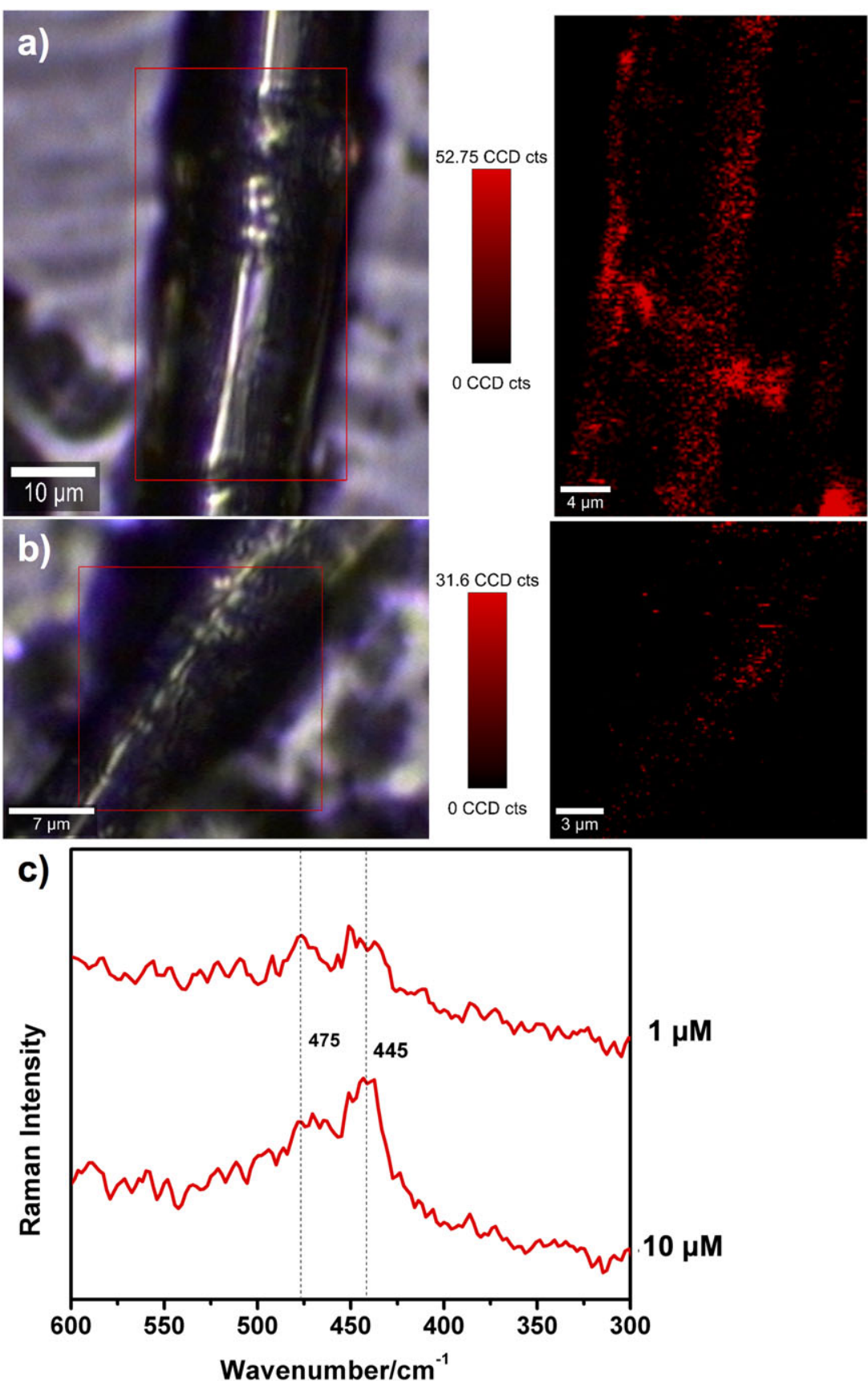

Figure 5. Optical image and Raman mapping obtained using the integrated intensity of the Raman band at $445 \mathrm{~cm}^{-1}$ in the SERS spectra of methylene blue adsorbed on Ag/linen after treating the fibers with methylene blue solutions a) $10 \mu \mathrm{M}(125 \times 200$ points per grid in a $25 \times 40 \mu \mathrm{m}$ area) and (b) $1 \mu \mathrm{M}$ ( $150 \times 150$ points per grid in a $20 \times 20 \mu \mathrm{m}$ area). The vertical bar shows the color profile in the Raman images; (c) average Raman spectrum obtained from the Raman image data. [Colour figure can be viewed at wileyonlinelibrary.com]

Also note that although Ag NPs still show an absorption tail (Fig. 1(a)) that extends to $633 \mathrm{~nm}$ (wavelength of the excitation line), which could block light penetration at the fibers surfaces, there are surface regions of the fibers not silver coated, and therefore, the sample is semi-transparent at this wavelength (see SEM image on Fig. 1(b)). Second observation, and most intriguing, monomer-adsorbated species (blue region) were detected inside of the fibers but not the dimer species (red region, band at $445 \mathrm{~cm}^{-1}$ ). In this regards, the linen fibers seem to act as size selective membranes to molecular diffusion, allowing MB monomers to pass through the fibers into the interior, but limiting the diffusion of
MB dimers. However, this is a partial explanation because the formation of MB aggregates, at least in aqueous solution, tends to increase with decreasing amount of dye in solution, thus leading to dimer formation or even higher order aggregates. ${ }^{[9,14]}$ Although the behavior in solid matrices is expected to be different, a plausible interpretation should also take into account that the linen fibers act as an active host matrix, probably interacting electrostatically with MB molecules through the hydroxyl groups of cellulose ${ }^{[27,40]}$ and therefore limiting the formation of dimers and higher aggregates that arise mainly via hydrophobic interactions, and van der Waals forces, thus favoring the adsorption of MB monomers. ${ }^{[5,8,41,42]} \mathrm{A}$ 

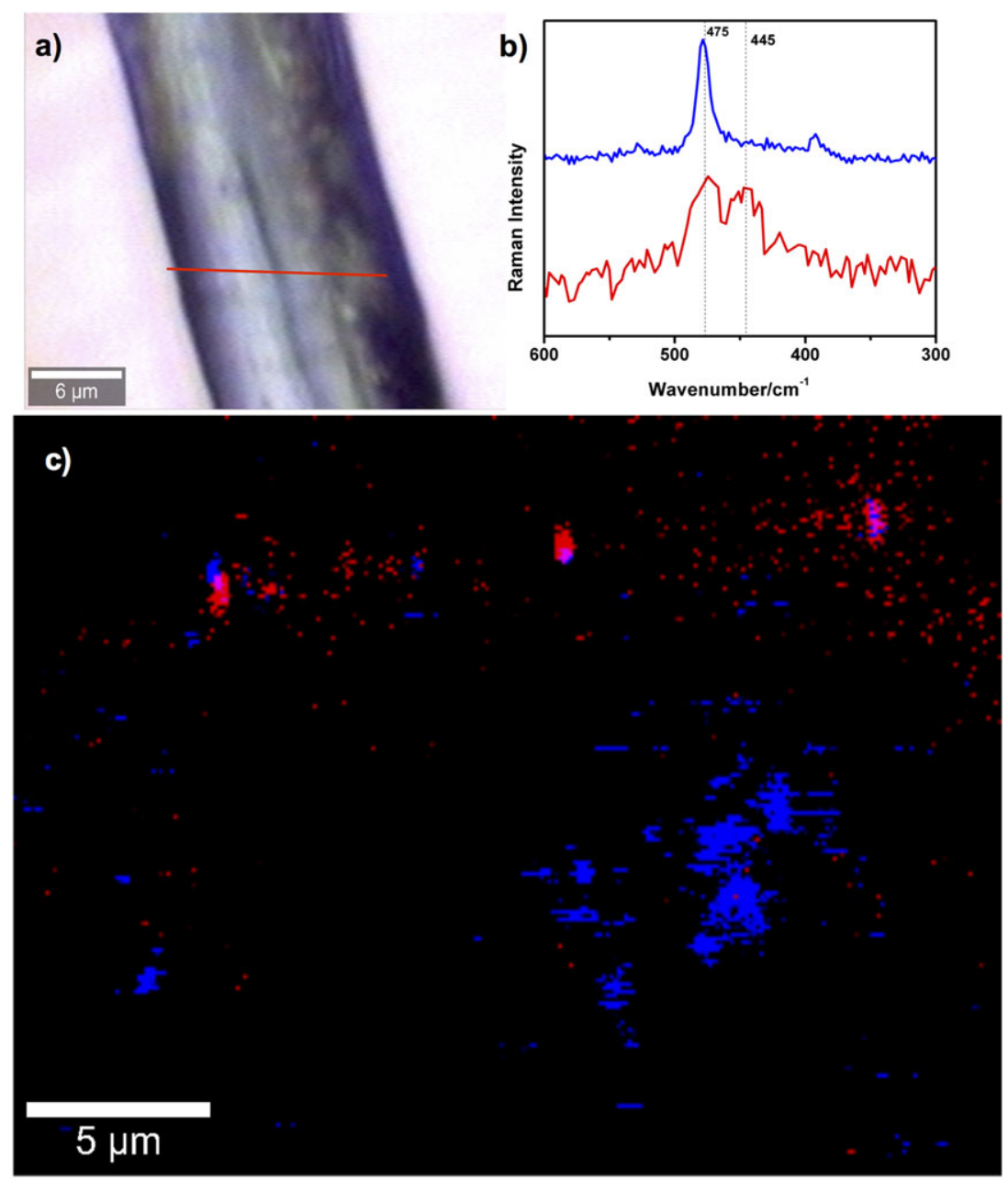

Figure 6. (a) Optical image; (b) Raman spectra of methylene blue forms used for the combined Raman image (633-nm excitation laser source, $270 \times 200$ points per grid in a $27 \times 20 \mu \mathrm{m}$ area); (c) combined deep Raman image of methylene blue $(100 \mu \mathrm{M})$ adsorbed on Ag/linen. [Colour figure can be viewed at wileyonlinelibrary.com]

possible effect due to the dry process was also considered in the interpretation of these observations. However, in such case, we would expect the dimers to be less abundant at the surface in relation to the fibers' interior, which dries slower, thus yielding a relative lower concentration in the dye that favors the formation of dimers in relation to monomers. ${ }^{[9,14]}$ Nevertheless, it should be highlighted that unlike conventional UV/vis absorption measurements (Fig. S2), Raman imaging gives more detailed information concerning the population of the MB forms within the textile fibers. Moreover, the SERS spectrum of the monomer suggests adsorption of the MB molecules in a perpendicular orientation relative to the Ag surface (Fig. 2(c), blue spectrum). Indeed, the band assigned to the thiazine rings bending in the plane $\left(475 \mathrm{~cm}^{-1}\right)$ is strongly enhanced, and the band at $1387 \mathrm{~cm}^{-1}$ is more intense than the band at $1618 \mathrm{~cm}^{-1}$, which is probably due to interaction of the $\mathrm{N}$ atoms with the Ag surface. On the other hand, the dimers (Fig. S3, SI) seem to interact with the metal via the fused phenyl and thiazine rings, involving the $\mathrm{N}$ and $\mathrm{S}$ donor atoms leading to the high intensity of the bands assigned at 1618,1387 , and $800 \mathrm{~cm}^{-1}$ (Fig. 2(c), red spectrum). ${ }^{[35,43]}$

In order to investigate the selective adsorption of the MB species onto Ag/linen composites, we have decided to investigate the dyeing process by using ethanolic solutions instead of aqueous solutions. This is because MB dissolved in ethanol occurs predominantly as monomers. ${ }^{[6]}$ Figure 7 shows the 2D Raman image and deep Raman image of MB $(100 \mu \mathrm{M})$ in ethanol using $\mathrm{Ag} /$ linen composites as SERS substrates. The 2D Raman image (Fig. 7(a)) shows that in this case the adsorption of the MB monomers (band at $445 \mathrm{~cm}^{-1}$ ) predominates in comparison with that of the MB dimers (band at $475 \mathrm{~cm}^{-1}$ ). However, unlike the case of the fibers that have been dyed using an aqueous solution of $M B$, the dimer species were also detected in the interior of fibers treated with an MB ethanolic solution (Fig. 7(b), both spectra, band at $445 \mathrm{~cm}^{-1}$ ). Although a weak Raman band was detected in this case, when using ethanol as the solvent, probably the diffusion of $\mathrm{MB}$ species within the fibers become facilitated, thus allowing dimer formation onto the Ag NPs but not in bulk solution.

Finally, we have used the data collected from the Raman spectra and Raman maps in order to obtain a semi-quantitative assessment of the relative amount of the MB forms in the linen fibers. The data are summarized in Table 1, in which the areas of deconvoluted Raman bands (Fig. S4, SI) have been compared with the colored regions in the Raman maps. Hence, the comparison of the areas of the bands at 445 and $475 \mathrm{~cm}^{-1}$ corresponding to the monomer and dimer species, respectively, suggest that the monomer species is in higher amount in the fibers, as compared with the dimer, for all the situations under analysis. Note that this conclusion cannot be withdrawn solely based on the analysis of the Raman images because both forms appear in the regions assigned as red (monomers 

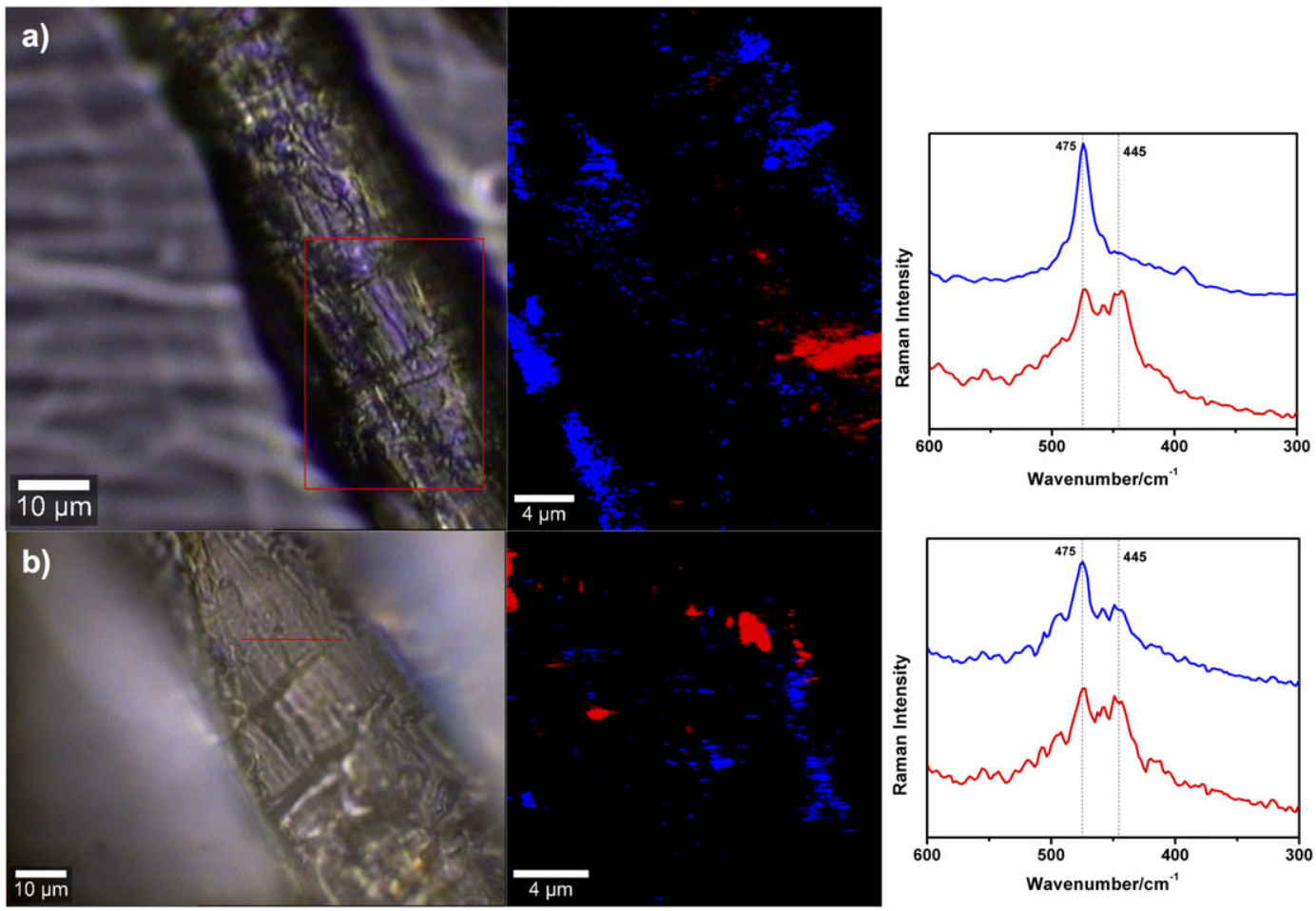

Figure 7. Optical photograph and combined Raman image $(175 \times 225$ points per grid in a $25 \times 35 \mu \mathrm{m}$ area $)(\mathrm{a})$ and optical image and combined deep Raman image ( $200 \times 200$ points per grid in a $20 \times 20 \mu \mathrm{m}$ area) (b) using two different Raman spectra of methylene blue $(100 \mu \mathrm{M})$ in ethanol solution adsorbed on Ag/ linen composite; (c) Raman spectra used for the combined Raman image (633 nm excitation laser source). [Colour figure can be viewed at wileyonlinelibrary.com]

\begin{tabular}{|c|c|c|c|c|}
\hline Figure & & Region under analysis & Raman band area & Raman imaging area (\% pixels) \\
\hline \multirow[t]{2}{*}{2} & Blue & \multirow{2}{*}{ SURFACE } & $8643.9(M)+0(D)$ & 0.61 \\
\hline & Red & & $4690.8(M)+6388.2(D)$ & 0.92 \\
\hline \multirow[t]{2}{*}{6} & Blue & \multirow{2}{*}{ INTERIOR } & $300.0(M)+0(D)$ & 0.98 \\
\hline & Red & & $56.8(M)+125.9(D)$ & 0.12 \\
\hline \multirow[t]{2}{*}{$7 a$} & Blue & \multirow{2}{*}{ SURFACE } & $6478.3(M)+0(D)$ & 4.04 \\
\hline & Red & & $6359.7(M)+2728.0(D)$ & 0.97 \\
\hline \multirow[t]{2}{*}{$7 b$} & Blue & \multirow{2}{*}{ INTERIOR } & $193.0(M)+50.0(D)$ & 0.96 \\
\hline & Red & & $298.9(M)+98.7(D)$ & 1.10 \\
\hline
\end{tabular}

and dimers). Interestingly, both the band areas data and Raman image analysis indicate that the amount of monomer in the interior of the fibers tend to be weighted in relation to the dimers, as discussed before. This analysis also demonstrates that the number of blue pixels and area of the band at $445 \mathrm{~cm}^{-1}$ (blue tracing), corresponding to the monomer species, is higher than for the corresponding dimer species, when linen-treated fibers using $M B$ in ethanol have been analyzed and compared with the fibers analogues treated in aqueous solution. Furthermore, image analysis of the depth Raman data (Fig. 7(b)) shows that for fibers treated with $M B$ in ethanol the dimer species are present in both spectra (blue and red tracings), but the area corresponding to such species is smaller than the corresponding area for monomer. The pixel analysis demonstrates that the number of red pixels is higher than the blue ones when considering a surface analysis; however, area estimations suggest that the monomer species is preferentially adsorbed onto Ag NPs located in the interior of the fibers.

\section{Conclusions}

The increasing use of antimicrobial textile products containing $\mathrm{Ag}$ has driven the interest and also the need for new monitoring techniques for these products. Following our recent interest in using a combination of SERS techniques and Raman imaging to characterize such fibers, this study explores these methods for the identification of different molecular forms of organic dyes (e.g. MB) used as textile colorants. In particular, this research has shown the possibility to distinguish the distribution of the monomer and dimer forms of MB over the linen fibers enriched in Ag NPs. The type of MB adsorbates onto the Ag NPs seems to depend on their location within the fibers and also on the dye solution composition. Thus, at the surface of the fibers, a mixture of MB species was detected; however, the monomer form is in higher amount in the fibers as compared with the dimer, using this substrate and experimental setup. While both forms are in equilibrium in bulk solution and 
therefore tend to adsorb at Ag NPs located at the surface of the treated fibers, it seems that dimer adsorption in the fibers interior is limited. A tentative explanation takes into account the conjugation of two factors, a size selective diffusion process mediated by the fibers and the type of chemical interactions occurring between the fibers and $M B$ that in the internal regions favors the formation of the monomer instead of dimers.

\section{Acknowledgements}

This work was developed within the scope of the project CICECO-Aveiro Institute of Materials, POCI-01-0145-FEDER-007679 (FCT Ref. UID/CTM/50011/2013), financed by national funds through the FCT/MEC and when appropriate co-financed by Fundo Europeu de Desenvolvimento Regional (FEDER) under the PT2020 Partnership Agreement. S. Fateixa thanks Fundação para a Ciência e Tecnologia (FCT) for the Grant SFRH/BPD/93547/2013.

\section{References}

[1] F. L. Arbeloa, I. L. Gonzalez, P. R. Ojeda, I. L. Arbeloa, J. Chem. Soc. Faraday Trans. 1982, 78, 989.

[2] P. R. Ojeda, I. A. K. Amashta, J. R. Ochoa, I. L. Arbeloa, J. Chem. Soc. Faraday Trans. 1988, 84, 1.

[3] R. Gvishi, R. Reisfeld, Chem. Phys. Lett. 1989, 156, 181.

[4] G. N. Lewis, O. Goldschmid, T. T. Magel, J. Bigeleisen, J. Am. Chem. Soc. $1943,65,1150$.

[5] E. Morgounova, Q. Shao, B. J. Hackel, D. D. Thomas, S. Ashkenazi, J. Biomed. Opt. 2013, 18, 56004

[6] H. Kobayashi, M. Sasaki, N. Ohsawa, K. Yasuda, M. Kotani, J. Phys. Chem. C 2007, 111, 268.

[7] A. Ghanadzadeh, A. Zeini, A. Kashef, M. Moghadam, J. Mol. Liq. 2008, 138, 100.

[8] K. Patil, R. Pawar, P. Talap, Phys. Chem. Chem. Phys. 2000, 2, 4313.

[9] L. Antonov, G. Gergov, V. Petrov, M. Kubista, J. Nygren, Talanta 1999, 49, 99.

[10] A. Ghanadzadeh, M. A. Zanjanchi, Spectrochim. Acta, Part A 2001, 57, 1865.

[11] A. Ghanadzadeh, M. A. Zanjanchi, R. Tirbandpay, J. Mol. Struct. 2002, 616,167

[12] K. Fujita, K. Taniguchi, H. Ohno, Talanta 2005, 65, 1066.

[13] A. Mishra, R. K. Behera, P. K. Behera, B. K. Mishra, G. B. Behera, Chem. Rev. 2000, 100, 1973.

[14] K. Fujita, K. Taniguchi, H. Ohno, Talanta 2005, 65, 1066.

[15] Z. Klika, P. Čapková, P. Horáková, M. Valášková, P. Malý, R. Macháň, M. Pospíšil, J. Colloid Interface Sci. 2007, 311, 14.

[16] S. H. A. Nicolai, J. C. Rubim, Langmuir 2003, 19, 4291.

[17] W. Spencer, J. R. Sutter, J. Phys. Chem. 1979, 83, 1573.
[18] J. Bujdák, N. lyi, T. Fujita, Clay Miner. 2002, 37, 121.

[19] J. Bujdák, N. Iyi, Y. Kaneko, R. Sasai, Clay Miner. 2003, 38, 561.

[20] J. Bujdák, M. Janek, J. Madejová, P. Komadel, Clay Clay Miner. 2001, 49, 244.

[21] R. R. Naujok, R. V. Duevel, R. M. Corn, Langmuir 1993, 9, 1771.

[22] G. McNay, D. Eustace, W. E. Smith, K. Faulds, D. Graham, Appl. Spectrosc. 2011, 65, 825 .

[23] A. J. Haes, S. Zou, J. Zhao, G. C. Schatz, R. P. Van Duyne, J. Am. Chem. Soc. 2006, 128, 10905.

[24] D. Cunningham, R. E. Littleford, W. E. Smith, P. J. Lundahl, I. Khan, D. W. McComb, D. Graham, N. Laforest, Faraday Discuss. 2006, 132, 135.

[25] W. Li, P. H. C. Camargo, X. Lu, Y. Xia, Nano Lett. 2009, 9, 485.

[26] F. Gessner, C. C. Schmitt, M. G. Neumann, Langmuir 1994, 10, 3749.

[27] S. Fateixa, M. Wilhelm, H. I. S. Nogueira, T. Trindade, J. Raman Spectrosc. 2016, 47, 1239.

[28] P. A. A. P. Marques, H. I. S. Nogueira, R. J. B. Pinto, C. P. Neto, T. Trindade, J. Raman Spectrosc. 2008, 39, 439.

[29] S. Fateixa, H. I. S. Nogueira, T. Trindade, Phys. Chem. Chem. Phys. 2015, $17,21046$.

[30] R. Core Team, R: A Language and Environment for Statistical Computing, R Foundation for Statistical Computing, Vienna, Austria, 2014 URL http://www.R-project.org/.

[31] R. Bivand, F. Leisch, M. Maechler, pixmap: Bitmap Images ("Pixel Maps"). R package version 0.4-11, 2011. URL http://CRAN.R-project.org/ package=pixmap

[32] E. Kort, rtiff: Read and Write TIFF Files. R package version 1.4.5, 2015. URL http://CRAN.R-project.org/package=rtiff

[33] L. Zhong, Y. Hu, D. Xing, in Pacific Rim Conference on Lasers and ElectroOptics (Ed: C.-T. Digest), IEEE, Shanghai, China, 2009.

[34] G.-N. Xiao, S.-Q. Man, Chem. Phys. Lett. 2007, 447, 305.

[35] X. Dong, H. Gu, J. Kang, X. Yuan, J. Wu, Colloids Surf. A Physicochem. Eng. Asp. 2010, 368, 142.

[36] P. H. B. Aoki, D. Volpati, W. Caetano, C. J. L. Constantino, Vib. Spectrosc. 2010, $54,93$.

[37] P. H. B. Aoki, P. Alessio, A. Riul, J. A. De Saja Saez, C. J. L. Constantino, Anal. Chem. 2010, 82, 3537.

[38] P. H. B. Aoki, P. Alessio, J. A. De Saja, C. J. L. Constantino, J. Raman Spectrosc. 2010, 41, 40.

[39] N. G. Tognalli, A. Fainstein, C. Vericat, M. E. Vela, R. C. Salvarezza, J. Phys. Chem. B 2006, 110, 354.

[40] D. Suteu, G. Biliuta, L. Rusu, S. Coseri, G. Nacu, Environ. Eng. Manag. J. 2015, 14, 525.

[41] R. Sanan, T. S. Kang, R. K. Mahajan, Phys. Chem. Chem. Phys. 2014, 16, 5667.

[42] O. Yazdani, M. Irandoust, J. B. Ghasemi, S. Hooshmand, Dyes Pigments 2012, 92, 1031

[43] S. Dutta Roy, M. Ghosh, J. Chowdhury, J. Raman Spectrosc. 2015, 46, 451.

\section{Supporting information}

Additional Supporting Information may be found online in the supporting information tab for this article. 